\title{
PRINSIP KESANTUNAN BERDASARKAN MAKSIM LEECH DALAM KUMPULAN NASKAH DRAMA GENG TOILET KARYA SOSIAWAN LEAK DAN RELEVANSINYA SEBAGAI BAHAN AJAR TEKS DRAMA DI SEKOLAH MENENGAH ATAS
}

\author{
Vinsca Sabrina Claudia, Ani Rakhmawati, Budi Waluyo \\ Universitas Sebelas Maret \\ Surel: vinscaclaudia@gmail.com
}

\begin{abstract}
Abstrak:Penelitian ini bertujuan untuk mendeskripsikan (1) bentuk tindak tutur dalam dialog kumpulan naskah drama Geng Toilet; (2)prinsip kesantunan dalam dialog kumpulan naskah drama Geng Toilet; (3) relevansi kumpulan naskah drama Geng Toilet sebagai bahan ajar pembelajaran teks drama di Sekolah Menengah Atas. Jenis penelitian yang digunakan dalam penelitian ini adalah deskriptif kualitatif. Hasil Penelitian ini menunjukkan bahwa, tindak tutur dalam dialog kumpulan naskah drama Geng Toilet berdasarkan ujaran yang mengandung tindakan meliputi tindak tutur lokusi, ilokusi, dan perlokusi. Adapun tindak tutur berdasarkan modus kalimatnya meliputi tindak tutur langsung dan tindak tutur tidak langsung. Selanjutnya, prinsip kesantunan dalam dialog kumpulan naskah drama Geng Toilet meliputi maksim kecocokan atau permufakatan, maksim kemurahan atau kedermawanan, maksim penerimaan atau pujian atau penghargaan, maksim kerendahan hati atau kesederhanaan, dan maksim kesimpatisan. Hasil penelitian ini juga menunjukkan bahwa kumpulan naskah drama Geng Toilet dapat dijadikan sebagai bahan ajar di Sekolah Menengah Atas.
\end{abstract}

Kata Kunci: naskah drama, tindak tutur, prinsip kesantunan.

\section{PRINCIPLES OF POLITENESS BASED ON LEECH MAXIM IN GENG TOILET DRAMA BY SOSIAWAN LEAK AND ITS RELEVANCE LEARNING MATERIAL OF DRAMA TEXT IN SENIOR HIGH SCHOOL}

\begin{abstract}
The research aims to explain and describe (1) speech acts in the dialogue collection of drama text Geng Toilet; (2) the principle of politeness in the dialogue collection of drama text Geng Toilet; (3) the relevance collection of drama text Geng Toilet as a teaching material for drama text in High School. The method use in this research is descriptive qualitative. The result of the research indicates the result of the research indicates the speech act in the collection of the drama text Geng Toilet based on speech that contains action include locution, illocution, and perlocution. While, speech acts based on the sentence mode include direct speech acts and indirect speech acts.Next, the principle of politeness in the dialogue collection of drama text Geng Toilet includes maxim of agreement or consent, maxim of generosity, maxim acceptance or praise or appreciation, maxim of humility or simplicity, and maxim of sympathy. the collection of drama text Geng Toilet can be used as a teaching materials for drama text in High School.
\end{abstract}

Keywords: drama text, specch acts, the principle of politeness.

PENDAHULUAN

Pembelajaran sastra di sekolah merupakan pembelajaran sebagai krea-tivitas dan keterampilan berbahasa siswa yang mencakup lima kompetensi yaitu mendengarkan, membaca, me-mirsa, berbicara, dan menulis. Semen-tara itu, pembelajaran sastra di sekolah menurut 
Ismawati (2013: 1) dalam pe-nelitian Kirana, Suwandi, dan Anindyarini (2015:1) dinyatakan bahwa pembelajaran yang menyangkut seluruh aspek sastra, meliputi: teori sastra, sejarah sastra, kritik sastra, sastra perbandingan, dan apresiasi sastra. Pembelajaran sastra yang ideal harus bermuara pada kegiatan apresiasi sastra. Salah satu yang diajarkan dalam jenjang pendidikan menengah adalah pembelajaran drama.

Pembelajaran drama di sekolah dapat diklasifikasikan ke dalam dua golongan, yaitu: (1) pembelajaran teks drama yang termasuk sastra, dan (2) pembelajaran drama yang termasuk bidang teater. Menurut Waluyo (2003: 158-159) pengajaran drama meru-pakan pengajaran sebagai penunjang pemahaman bahasa berarti untuk me-latih keterampilan membaca (teks drama) dan menyimak atau mende-ngarkan (dialog pertunjukan drama. Sementara sebagai penunjang latihan penggunaan bahasa artinya melatih keterampilan menulis (teks drama se-derhana, resensi drama, resensi pemen-tasan) dan wicara (melakukan pemen-tasan drama).

Kesulitan guru dalam penga-jaran teks drama di kelas adalah dalam hal memperoleh naskah-naskah pen-dek dengan lama pentas (durasi) 30 menit. Kebanyakan teks drama dari karya para dramawan berdurasi minimal 90 atau 360 menit. Drama-drama yang ditulis para dramawan cocok untuk pentas sekolah (bukan kelas). Untuk pementasan kelas, murid-murid perlu menyusun teks sendiri. Selanjutnya teks tersebut didiskusikan untuk diperbaiki bersama disesuaikan dengan kondisi dan situasi kelas atau sekolah.

Penelitian ini mengulas mengenai kumpulan naskah drama Geng Toilet karya Sosiawan Leak yang dapat dijadikan sebagai alternatif dalam pembelajaran teks drama di SMA. Di dalam kumpulan naskah drama Geng Toilet terdapat beberapa naskah yang berdurasi pendek dan sangat cocok untuk pembelajaran teks drama di kelas. Selain itu, di dalam naskah terdapat dialog antarpemain yang merupakan unsur dalam sebuah pementasan. Dalam dialog terkandung sebuah tuturan yang dapat digunakan untuk menyampaikan beberapa maksud. Sebaliknya, satu maksud dapat disampaikan dengan beraneka ragam tuturan. Oleh sebab itu, dengan adanya pemaknaan ragam tuturan dapat ditemukan masalah mengenai maksud dari beberapa dialog yang dituturkan oleh pemain.

Terkait penelitian ini tentang struktur internal dan prinsip kesan-tunan, ada beberapa penelitian yang relevan. Salah satu penelitian oleh Chandra Endrasmoro (2015) yang berjudul "Unsur Pembangun Kumpulan Naskah Drama Geng Toilet Karya Sosiawan Leak". Tujuan pene-litian ini adalah untuk mendes-kripsikan unsur pembangun pada kum-pulan naskah drama Geng Toilet karya Sosiawan Leak. Hasil dari penelitian kumpulan naskah drama Geng Toilet ini diharapkan dapat menambah referensi baru khususnya tentang kajian naskah drama dan bisa digunakan se-bagai masukan untuk meningkatkan pengetahuan tentang drama dan teks drama. Penelitian tersebut mempunyai persamaan dengan penelitian ini yaitu menggunakan metode kualitatif dengan menggunakan sumber data yaitu dari kumpulan naskah dra-ma Geng Toilet karya Sosiawan Leak.

Penelitian selanjutnya, dila-kukan oleh Rodhiati Rahmawati (2014) berjudul "Analisis Kesantunan Berbahasa di Lingkungan Terminal Sekitar Wilayah Bojonegoro dengan Prinsip Kesantunan Leech". Hasil dari penelitian kesantunan berbahasa di lingkungan terminal khususnya di Ter-minal Bojonegoro menunjukkan bahwa tuturan yang ada di lingkungan Terminal khususnya di terminal sekitar wilayah Bojonegoro yang dituturkan oleh para calo, pedagang asongan, sopir dan 
kondektur terdapat pelanggaran enam maksim prinsip kesantunan Leech. Penelitian ini mempunyai kesamaan yaitu menganalisis tentang kesantunan berbahasa tindak tutur dialog di lingkungan terminal, hal tersebut terdapat dalam naskah drama berjudul Geng Toilet yang berada di kumpulan naskah drama Geng Toilet karya Sosiawan Leak.

Pragmatik merupakan salah satu bidang linguistik yang mem-punyai bidang kajian baru. Sesuai dengan pendapat Leech dan Wijana (dalam Wijana dan Rohmadi, 2011: 6) perkembangan pragmatik disebabkan semakin tingginya tingkat kesadaran para ahli bahasa terhadap pemahaman pragmatik, yakni bagaimana bahasa itu digunakan dalam komunikasi.

Tindak tutur merupakan unit analisis atau satuan kajian pragmatik, yaitu cabang ilmu bahasa yang meng-kaji bahasa dari aspek pemakaian aktualnya. Teori tindak tutur pertama kali diungkapkan oleh Austin (1962) (dalam Sumarlam, dkk., 2017: 31 dan 37-42) yang mendefinisikan bahwa speech act (tindak tutur) merupakan konsep bertutur yang digunakan pe-nutur dengan mitra tutur dalam per-cakapan dan membedakan tiga jenis tindakan yang berkaitan dengan ujaran yaitu: (1) tindak tutur lokusi (Locu-tionary Act), (2) tindak tutur ilokusi (Illocutionary Act), dan (3) tindak tutur perlokusi(Perlocutionary Act).

Berdasarkan pemilihan tindak tutur yang dikemukakan oleh Austin, Searle, Nababan, dan Wijana di atas menunjukkan adanya macam-macam tindak tutur. Pengklasifikasian tindak tutur oleh Austin, Searle, dan Nababan berdasarkan penggunaan bahasa dalam situasi percakapan antara dua pihak, yaitu tindak tutur lokusi (locutionary act), tindak tutur illokusi (Illocutionary act), dan tindak tutur perlokusi.

Menurut Wijana (1996: 4) (dalam Rohmadi, 2004: 33-35) mengklasifikasikan tindak tutur berdasarkan modus dan kalimatnya dibagi menjadi dua, yaitu (1) tindak tutur langsung dan tindak tutur tidak langsung, serta (2) tindak tutur literal dan tindak tutur tak literal.

Adapun jenis-jenis tindak tutur yang dikemukakan oleh Yule (2006: 95-96) dikemukakan bahwa secara pendekatan yang berbeda terhadap pemilahan tipe-tipe tindak tutur dibuat berdasarkan strukturnya, yakni (1) tindak tutur langsung (direct speech act) dan (2) tindak tutur tidak langsung (indirect speech act).

Kesantuanan berbahasa meru-pakan sebuah peraturan di dalam percakapan yang mengatur penutur dan petutur untuk memperhatikan so-pan santun dalam berbahasa. Sulistyo (2013: 27) menyatakan kesantunan atau kesopanan adalah perlakuan suatu konsep yang tegas yang berhubungan dengan tingkah laku sosial yang sopan yang terdapat di budaya atau suatu masyarakat. Prinsip kesantunan (keso-panan) menurut Leech (1983) (dalam Sulistyo, 2013: 27-29) dibagi menjadi enam maksim yakni: (1) maksim kebi-jaksanaan (tact maxim), (2)maksim kemurahan atau kedermawanan (gene-rosity maxim), (3) maksim penerimaan atau pujian atau penghargaan (appro-bation maxim), (4) maksim keren-dahan hati atau kesederhanaan (mo-desty maxim), (5) maksim keco-cokan/permufakatan (agreement ma-xim), dan (6) maksim kesimpatisan (sympathy maxim).

Drama merupakan potret kehi-dupan manusia yang diproyeksikan di dalam sebuah pementasan. Waluyo (2006: 1) menyatakan drama meru-pakan potret kehidupan manusia, po-tret suka duka, pahit manis, hitam pu-tih kehidupan manusia. Selanjutnya, naskah drama atau naskah lakon pada umumnya disebut skenario, berupa su-sunan babak atau adegan sebagai penuangan pemikiran oleh seorang pengarang. Menurut Rusyana (1987: 140) dalam penelitian Asmaniah (2015: 220) menyebutkan bahwa naskah drama 
merupakan sebuah karangan tertulis yang berisikan sebuah cerita atau kisah yang menggambarkan kehidupan serta watak pemain untuk kebutuhan satu pagelaran atau pemen-tasan drama. Adapun menurut Waluyo (2006: 3) batasan tentang drama naskah merupakan salah satu jenis karya sastra yang ditulis dalam bentuk dialog yang didasarkan atas konflik batin dan mempunyai kemungkinan dipen-taskan. Sebuah dasar naskah drama menurut Widyahening (2012: 144) yaitu adanya konflik manusia yang biasanya terbangun oleh pertentangan antara tokoh-tokohnya. Dengan pertikaian itu muncullah dramatic action. Daya pikir suatu naskah drama ditentukan oleh kuatnya dramatic action ini.

Pengajaran drama di sekolah dapat ditafsirkan dua macam, yaitu pengajaran teori drama atau penga-jaran apresiasi drama. Masing-masing juga terdiri atas dua jenis, yaitu pengajaran teori tentang teks (naskah) drama, dan pengajaran tentang teori pementasan drama. Menurut Waluyo (2003: 153-155) pengajaran apresiasi dibahas naskah drama dan apresiasi pementasan drama. Dalam apresiasi yaitu naskah maupun pementasan. Tampaknya kedua hal ini penting, hanya saja tekanannya harus pada aspek apresiasi.

Saat ini disadari, bahwa drama semakin popular di sekolah. Calon guru tentu saja harus mampu mengajarkan drama, baik itu dalam hal teori maupun dalam hal apresiasi, baik itu dalam hal naskah ataupun dalam hal pementasan. Lewat dramatisasi, di-mungkinkan suatu pengetahuan, dapat menjadi sikap, dan kemudian menjadi tingkah laku (penghayatan dan pengalaman). Selama ini guru sastra masih terpaku pada penilaian dan tujuan mengajar dalam aspek kognitif.

Harus diakui, bahwa naskah-naskah drama memang sulit didapat. Di depan sudah disebutkan, bahwa jalan terbaik untuk mendapatkan nas-kah adalah lewat bank naskah pada setiap teater ternama. Akan tetapi yang terbaik lagi jika guru dan murid men-coba menciptakan naskah-naskah sederhana. Sebagai contoh menas-kahkan suatu role playing atau cerita-cerita daerah setempat.Guru drama hendaknya mampu memperkenalkan drama kepada siswa, kemudian mem-bimbing apresiasi drama, membuat mereka menyenangi, menggemari, dan menjadikan drama sebagai salah satu bagian yang menyenangkan dalam kehidupan mereka. mereka membaca sendiri atau menonton pementasannya.

\section{METODE PENELITIAN}

Penelitian ini dilakukan selama enam bulan dengan menggunakan kumpulan naskah drama Geng Toilet karya Sosiawan Leak yaitu bulan Februari - Juli 2018. Pendekatan yang digunakan dalam penelitian ini berupa penelitian kualitatif dengan jenis pe-nelitian deskriptif. Data yang dikumpulkan dengan cara mengkaji dokumen yang berupa kumpulan naskah drama yang berjudul Geng Toilet karya Sosiawan Leak yang terdiri dari empat naskah yaitu Demo Kaum Binatang, Geng Toilet, Overdosis, dan Ujian. Teknik pengambilan sampel dengan menggunakan teknik purposive sampling. Narbuko dan Achmadi (2016: 116) menyatakan teknik pur-posive sampling merupakan teknik berdasarkan pada ciri-ciri atau sifat-sifat tertentu yang diperkirakan me-miliki kesamaan yang ada dalam populasi yang sudah diketahui sebelumnya.Teknik pengumpulan data menggunakan menggunakan analisis dokumen dan wawancara. Uji validitas data yang digunakan adalah triangulasi teori dan triangulasi sumber data. Ana-lisis data yang digunakan adalah teknik analisis jalinan atau mengalir, seperti yang dikemukakan oleh Miles dan Huberman (dalam Sugiyono, 2016: 91) dengan tiga komponen ana-lisis yaitu reduksi data, sajian data, dan penarikan simpulan. 


\section{HASIL DAN PEMBAHASAN}

Tindak Tutur Dialog dalam Kumpulan Naskah Drama Geng Toilet

Menurut Austin (1962) (dalam Sumarlam, dkk., 2017: 37-42) mengemukakan tindak tutur dialog dibedakan menjadi tiga jenis berdasarkan tindakan yang berkaitan dengan ujaran yaitu (1) tindak tutur lokusi (locu-tionary act), (2) tindak tutur ilokusi (illocutinary act), dan (3) tindak tutur perlokusi (perlocutionary act). Adapun menurut Yule (2006: 95-96), bahwa secara pendekatan yang berbeda terhadap pemilahan tipe-tipe tindak tutur dibuat berdasarkan strukturnya yaitu tindak tutur langsung (direct speech act) dan tindak tutur tidak langsung (indirect speech act).

Berikut hasil temuan data yang menunjukkan tindak tutur dialog kumpulan naskah drama Geng Toilet karya Sosiawan Leakberdasarkan tindakan yang berkaitan dengan ujaran.

Pertama, tindak tutur naskah drama Demo Kaum Binatangterdapat 19 jumlah data untuk masing-masing tindak tutur yaitu: $7(37 \%)$ me-ngandung tindak tutur lokusi, 6 (32\%) mengandung tindak tutur ilokusi, dan $6(32 \%)$ mengandung tindak tutur per-lokusi. Tabel 4.2. Tindak Tutur Dialog Nas-kah Drama Demo Kaum Binatang

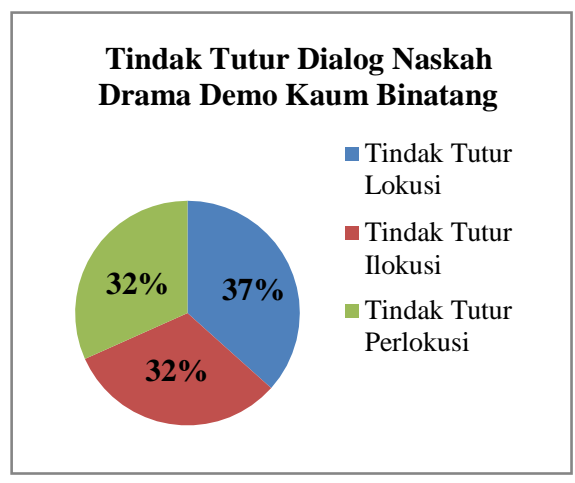

Tabel diatas menunjukkan bahwa tindak tutur lokusi lebih banyak digunakan, disusul dengan tindak tutur ilokusi dan perlokusi memiliki jumlah data yang sama.
Kedua, tindak tutur naskah drama Geng Toilet terdapat 31 jumlah data untuk masing-masing tindak tutur yaitu: $1(3 \%)$ mengandung tindak tutur lokusi, 17 (55\%) mengandung tindak tutur ilokusi, dan 13 (42\%) me-ngandung tindak tutur perlokusi.

Tabel 4.3. Tindak Tutur Dialog Naskah Drama Geng Toilet

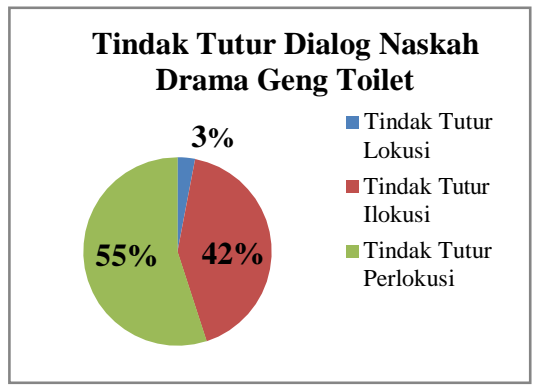

Tabel diatas menunjukkan bahwa tindak tutur perlokusi lebih ba-nyak digunakan, disusul dengan tindak tutur ilokusi, lalu tindak tutur lokusi.

Ketiga, tindak tutur naskah drama Overdosisterdapat 27 jumlah data untuk masing-masing tindak tutur yaitu: $5(19 \%)$ mengandung tindak tutur lokusi, 12 (44\%) mengandung tindak tutur ilokusi, dan 10 (37\%) mengandung tindak tutur perlokusi.

Tabel 4.4. Tindak Tutur Dialog Naskah Drama Overdosis

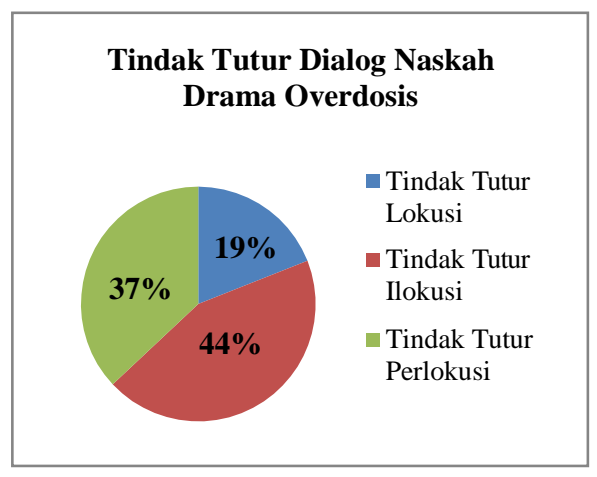

Tabel diatas menunjukkan bahwa tindak tutur perlokusi lebih ba-nyak digunakan, disusul dengan tindak tutur ilokusi, lalu tindak tutur lokusi. 
Ketiga, tindak tutur naskah drama Ujian terdapat 22 jumlah data untuk masingmasing tindak tutur yaitu: $1(5 \%)$

mengandung tindak tutur lokusi, $10(45 \%)$ mengandung tindak tutur ilokusi, dan 11 $(50 \%)$ mengandung tindak tutur perlokusi.

Tabel 4.5. Tindak Tutur Dialog Nas-kah Drama Ujian

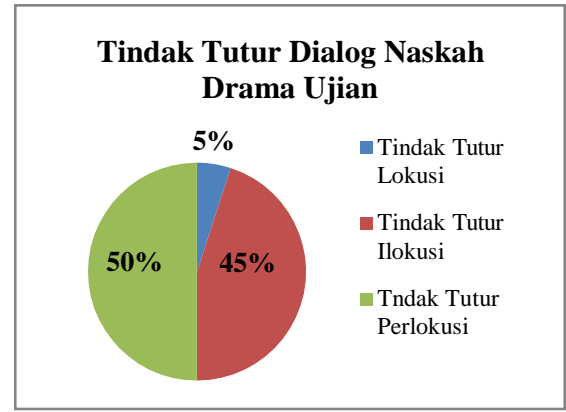

Tabel diatas menunjukkan bahwa tindak tutur perlokusi lebih ba-nyak digunakan, disusul dengan tindak tutur ilokusi, lalu tindak tutur lokusi.

\section{Tindak Tutur Lokusi}

(1) Narator: Serombongan binatang berjalan tergesa-gesa. Mereka tak tampak sedang berwisata. Atau latihan baris untuk peringatan tujuhbelasan.Mereka lebih mirip pengungsi karena bencana alam; kebakaran hutan, gunung meletus, banjir atau gempa yang rutin datang.Serombongan binatang bergegas. Mereka jelas bukan pengungsi perang. Juga bukan rombongan tawuran pelajar di kota besar. Mereka dipastikan bukan korban yang tunggang langgang dari bom hotel berbintang. Atau kumpulan teroris lokal apalagi internasional.Mereka juga bukan rombongan jamaah-jamaahan yang dianggap dalang kerusuhan.Bukan!

Pada Data (01) konteks ini terjadi ketika para binatang sedang mem-bentuk barisan. Mereka sambil ber-nyanyi kompak dan bersemangat. Dalam barisan depan, terdapat Narator yang menjadi pimpinan barisan para binatang. Tuturan dialog Narator ter-dapat tindak tutur lokusi dengan menyatakan sesuatu tentang kehidupan para kaum binatang tanpa mempe-ngaruhi yang ada disekitarnya. Tu-turan ini hanya menginformasikan bahwa terdapat serombongan binatang yang berjalan tergesagesa dengan menggambarkan seolah- olah serom-bongan pengungsi karena tempat tinggal mereka terkena bencana alam.

\section{Tindak Tutur Ilokusi}

(2) Kecruk: Tapi kan belum tentu begitu ta, Mbah?! (Berdiri) Mbah Kuncen juga belum membuktikan bahwa alat itu lebih ampuh... Wong, lihat barangnya saja belum! Itu rak baru katanya?! Jare,... Kenyataannya kan belum dicoba?!

Mbah Kuncen:(Menoleh Kecruk) Belum dicoba, piye??

Kecruk: (Mendekat) Dicoba ditandingkan! Didu!! Kalau kesaktian makam Kyai Congor Gosong, kan sudah terbukti?! Seluruh warga desa sudah tahu! Sudah pernah merasakan bagaimana keinginan-keinginan mereka terkabul berkat doa-doa, sajen dan slametan yang mereka lakukan di makam! Ya,... walaupun ada yang terlambat kesampaian atau kadang agak sedikit meleset dari harapan, itu kan wajar?! Yang penting tetep kesampaian, ta?! Lha kalau alat itu, siapa yang tahu? Siapa yang berani njamin? Lagi pula, alat itu katanya hanya khusus meramal masalah bencana, Mbah! Tidak bisa meramal soal lainnya!

Pada Data (02) konteks ini terjadi ketika Mbah Kuncen takut jika warga desa Demen Dugem tidak percaya lagi dengan makam Mbah Kyai Congor Gosong sehingga beralih ke alat de-teksi bencana yang diberikan oleh pemerintah. Kecruk sebagai 
anak buah Mbah Kuncen turut penasaran sebe-rapa hebat kekuatan makan Kyai Congor Gosong dengan alat deteksi bencana. Pada tuturan dialog Kecruk tersebut terdapat tindak tutur ilokusi asertif yang menawarkan sesuatu ter-hadap lawan bicaranya. Kecruk ingin tahu kekuatan yang dimiliki oleh makam Kyai Congor Gosong dengan alat deteksi bencana dari pemerintah pusat. Lalu, dia menawarkan kepada Mbah Kuncen untuk membandingkan ke-kuatan yang dimiliki oleh mereka. Nantinya, agar kekuatan yang dimiliki oleh keduanya terbukti dan diketahui oleh seluruh warga dukuh Masa De-pan. Menurutnya, alat deteksi bencana hanya bisa meramal bencana saja dan tidak bisa meramal yang lain.

\section{Tindak Tutur Perlokusi}

(3) Keledai: (Marah Ke Narator) Pak Dalang! Wedhus, Sampean iki! Mongsok kita mau diajak ke toilet?!

Narator:(Balik Marah Ke Keledai) Pakai ini dhong, kalau ngomong!? (Menunjuk Jidat). Jangan pakai ini! (Menggoyang Pantat). Dasar, keledai! Siapa yang ngajak ke sana?!

Keledai: Tadi, dalam cerita Sampean?! Wedhusi, mau mungkir?! Narator:Siapa yang cerita gitu?!

Kamu yang wedhus!

Keledai: Enak saja! Aku ini keledai! Wedhus!

Pada Data (03) konteks ini terjadi ketika para kaum binatang sedang melakukan eksplorasi gerakan secara bersama hingga berhenti secara sen-dirinya. Keledai kesal terhadap Na-rator jika para kaum binatang akan digiring ke toilet. Padahal maksud dari Narator akan dibawa ke lapangan agar terhindar dari bencana alam. Tuturan dialog Keledai terdapat tindak tutur perlokusi yang menimbulkan efek emosi terhadap lawan bicaranya yaitu Narator, sehingga menyebabkan tu-turan dari Keledai dan Narator menim-bulkan pertengkaran.
Sedangkan, hasil temuan data yang menunjukkan tindak tutur dialog kumpulan naskah drama Geng Toilet karya Sosiawan Leakberdasarkan tindakan yang berkaitan dengan strukturnya.

Pertama, dialog naskah drama Demo Kaum Binatang terdapat satu tindak tutur yaitu tindak tutur tidak langsung. Pada tindak tutur tidak langsung terdapat 4 jumlah data yang ditemukan.

Kedua,dialog naskah drama Geng Toilet terdapat satu tindak tutur yaitu tindak tutur langsung. Pada tindak tutur langsung terdapat 6 jumlah data yang ditemukan.

Ketiga,pada dialog naskah drama Overdosis terdapat 8 jumlah data, dengan masing-masing data yang ditemukan yaitu: 6 data mengandung tindak tutur langsung dan 2 data mengandung tindak tutur tidak langsung.

Keempat, dialog naskah drama Ujian terdapat 12 jumlah data, dengan masingmasing data yang ditemukan yaitu: 9 data mengandung tindak tutur langsung dan 3 data mengandung tindak tutur tidak langsung.

\section{Tindak Tutur Langsung}

(01) Karjo: Ke toilet dulu, Mas?

Barangkali bisa mengurangi stres?

Harto: Atau kalau belum ada yang mau dibuang ke toilet, makan roti dulu Mas? Atau minum? Murah kok. Atau kalau memang mau ke toilet, nggak asyik, Mas tanpa rokok. Rokoknya apa? Dagangan saya komplet, lho?!

Konteks dan Analisis: pada tuturan dialog Karjodan Harto tersebut terdapat tindak tutur langsung yang mendorong untuk melakukan suatu tindakan. Karjo menawarkan jasanya yaitu toilet sedangkan Harto menawarkan dagangannya kepada Slamet agar bisa mengurangi stres setelah dicopet tadi naik bis. Maksud tuturan Karjo yaitu untuk mengelabuhi Slamet agar tidak 
banyak bertanya tentang profesi yang dimilikinya.

\section{Tindak Tutur Tidak Langsung}

(02) Bu Tari: Kita ambil jalan pintas, terobosan yang lebih pasti!

Konteks dan Analisis: pada tuturan dialog $\mathrm{Bu}$ Tari mengandung tindak tutur tidak langsung yang menawarkan sesuatu kepada lawan bicaranya. $\mathrm{Bu}$ Tari menawarkan terobosan agar siswa lulus kepada $\mathrm{Bu}$ Linda bahwa dia sudah memikirkan dengan mengambil jalan pintas dengan terobosan yang pasti. Maksud di balik tuturan $\mathrm{Bu}$ Tari yaitu menawarkan kepada $\mathrm{Bu}$ Linda unruk melakukan kecurangan pada saat Ujian Nasional anak didik berlangsung.

\section{Prinsip Kesantunan Dialog dalam Kumpulan Naskah Drama Geng Toilet}

Setelah dilakukan analisis data yang ditemukan, terdapat wujud mak-sim dalam prinsip kesantunan dialog dalam kumpulan naskah drama Geng Toiletkarya Sosiawan Leak yaitu (1) maksim kemurahan atau keder-mawanan, (2) maksim penerimaan atau pujian atau penghargaan, (3) maksim kerendahan hati atau kese-derhanaan, (4) maksim kecocokan atau permufakatan, dan (5) maksim kesim-patisan.

Pertama, dialog naskah drama Demo Kaum Binatang terdapat satu maksim prinsip kesantunan yaitu mak-sim kecocokan atau permufakatan. Pada maksim kecocokan terdapat 3 jumlah data yang ditemukan.

Kedua, dialog naskah drama Geng Toilet terdapat tiga maksim prinsip kesantunan yaitu (1) maksim kemurahan atau kedermawanan, (2) maksim penerimaan atau pujian atau penghargaan, dan (3) maksim keren-dahan hati atau kesederhanaan. Pada maksim kemurahan terdapat 5 jumlah data yang ditemukan, lalu maksim penerimaan terdapat 1 jumlah data, sedangkan maksim kerendahan hati terdapat 3 jumlah data.

Ketiga, dialog naskah drama Overdosis terdapat dua maksim prinsip kesantunan yaitu (1) maksim pene-rimaan pujian atau penghargaan dan (2) maksim kecocokan atau permufakatan. Pada maksim pene-rimaan pujian terdapat 1 jumlah data yang ditemukan dan maksim keco-cokan terdapat 1 jumlah data,

Keempat, dialog naskah drama Ujian terdapat dua maksim prinsip kesantunan yaitu maksim kecocokan atau permufakatan dan maksim kesim-patisan. Pada maksim kecocokan ter-dapat 2 jumlah data yang ditemukan dan maksim kesimpatisan terdapat 1 jumlah data.

Maksim Kemurahan atau Keder-mawanan (01) Sarjono: (Marah) Crazy! Anda, jangan sembarangan ya?! Anda menuduh saya teman copet itu, ya?! (Maju)

Satrio: (Ketus) Lho?! Siapa yang menuduh begitu? Sampean sendiri, yang ngomong gitu, kok?! (Maju) Slamet: (Melerai) Alah,... sudah, sudah. Lha wong saya yang mau kecopetan saja nggak bingung kok! Mas-mas yang nggak jadi sasaran copet malah mau bertengkar. Coba, kalau tadi saya nggak jadi sasaran pencopet, apa Mas-mas juga akan tetap bertengkar?!

Pada Data (01) terdapat tuturan terjadi antarpenumpang, yaitu Sarjono, Satrio, dan Slamet. Sarjono dan Slamet se-dang meributkan orang yang sudah mencopet Slamet di dalam bis. Lalu, Sarjono tidak terima atas tuduhan yang diberikan oleh Satrio jika dia merupakan teman pecopet tersebut, te-tapi Satrio bersikeras dengan pendapatnya. Kekhawatiran atas pertengkaran tersebut diungkapkan oleh Slamet kepada Sarjono dan Satrio. Sarjono dan Satrio kebingungungan dengan ekspresinya, yang secara rea-listis dalam percakapan 
tersebut diatas Slamet yang mengalami kecopetan. Slamet berusaha untuk melerai per-tengkaran yang dilakukan oleh Sajono dan Satrio agar tidak meributkan masalah pencopet yang sudah terjadi.

\section{Maksim Penerimaan atau Pujian atau Penghargaan}

(02) Slamet: Oh, saya baru saja selesai kuliah Pak. Bulan kemarin diwisuda. Ini saya malah lagi muter-muter cari pekerjaan. Susah ya Pak, nyari kerjaan?! Saya sudah memasukkan 27 lamaran, baik di kantor pemerintah maupun suasta. (Membuka Tas Dan Menunjukkan Beberapa Bundel Berkas Lamaran) Ini, masih banyak yang akan saya masukkan lagi.

Satrio: (Sambil Memeriksa Bundel Lamaran) Wah, banyak sekali! Dik Slamet ini termasuk orang yang ulet, ya?! Pantang menyerah!

Pada Data (02) terdapattuturan di atas disampaikan oleh Slamet kepada Satrio. Slamet semula mengeluh ter-hadap dirinya yang sejak lulus kuliah hingga sekarang belum mendapatkan lapangan pekerjaan. Slamet sudah ber-keliling mencari pekerjaan hingga me-masukkan dua puluh tujuh lamaran di kantor pemerintahan maupun swasta dan belum ada hasilnya. Dia menceritakan kepada Satrio akan me-masukkan lamaran lebih banyak lagi. Satrio menunjukkan reaksinya dengan sangat kagum dan memuji terhadap usaha yang dilakukan oleh Slamet selama ini.

\section{Maksim Kerendahan Hati atau Kese- derhanaan}

(03) Slamet: (Berdiri) Apalagi kalau bukan teman?! Wong waktu saya keluar dari toilet, mereka berdua sudah nggak ada. Saya cari ke mana-mana nggak ketemu. Saya balik ke sini, saya kira mereka teman kalian!

Harto Dan Karjo: (Saling Memandang) Lho?! (BERDIRI)

Karjo: Kok Sampean berpikir begitu ta, Mas?!

Harto: Apa kami pantas jadi teman mereka?! Kami ini orang bodho.

Omongan mereka saja nggak ada satupun yang kami pahami, kok?!

Pada Data (03) terdapattuturan di atas diungkapkan oleh Slamet kepada Harto dan Karjo. Slamet datang kem-bali ke ruang tunggu penumpang untuk bertemu dengan Harto dan Karjo untuk menanyakan tentang keberadaan te-man-temannya yaitu Sarjono dan Sa-trio yang sudah mengambil barangbarangnya. Harto dan Karjo menjawab dengan merendah karena mereka hanya penjaga toilet dan pedagang asongan sehingga tidak pantas bergaul dengan mereka yang berpenampilan menarik dan gaya bicaranya sudah seperti orang atasan.

\section{Maksim Permufakatan}

(04) Babi: (Menyeruak Dari Rombongan Binatang) Grook, ... groook, ... itu masalahnya. Kita inisama-sama korban pelecehan. Nama kita dijadikan umpatan. Bertahun-tahun berjalan, mengadu ke sana-ke mari, hanya untuk membersihkan nama kita. Nama binatang yang dilecehkan manusia!

Bangsat: (Nangkring Di Salah Satu Pundak Binatang Yang Tertinggi) Betul!! Sejak nenek moyangku, Bangsat namaku. Kutu yang bau. Binatang yang gigitannya bikin merah dan gatal. Tapi bukan lantas namaku boleh dijadikan umpatan. Aku bau karena manusia. Aku menggigit karena tersedia bokong manusia. Para bokong yang seenak udel nongkrong tanpa merawat tempat duduknya. Aku, pejuang 
bangsa Bangsat! Mewakili kaum

Bangsat, tak rela martabat kaumku

dilecehkan! Aku, putra daerah asli

kaum Bangsat, bergabung dengan

para ksatria, untuk membela nama!

Bukan malah sebaliknya, jadi olok-

olokan kalian! Sekali Bangsat, tetap

Bangsat!" (Berteriak) Hidup Kaum

Bangsat..!!

Pada Data (04) terdapat tuturan tersebut mengandung maksim permu-fakatan atau biasa disebut sebagai maksim kecocokan karena antara Babi dan Bangsat terjadi kecocokan. Tu-turan mereka mengandung kese-pakatan jika nama binatang sering dijadikan korban pelecehan dan dija-dikan umpatan oleh manusia. Mereka tidak terima dan berusaha membersihkan nama yang sudah dilecehkan oleh perilaku manusia.

\section{Maksim Kesimpatisan}

Patria: (Berdiri) Biar saja! Apa bedanya hamba Tuhan dan bukan? Apa bedanya orang baik dan tidak baik di hadapannya? Lihat, berapa banyak orang tidak sembahyang, tidak berdoa, tidak patuh kepadanya? Lalu lihat! (MenunjukNunjuk) Sebagian besar mereka malah mendapat kemudahan dalam hidupnya!

Silvi: Patria! Sadar Patria, sadar.... Kamu kok jadi ngawur begitu sih? Nggak nyangka aku kalau kamu punya pikiran begitu?

Patria: Nyatanya, kamu bisa lihat sendiri Silvi! Diantara teman-teman kita yang lulus, berapa sih yang taat sama tuhan? Kok mereka dikasih lulus sama tuhan? Kok aku nggak? Apa kurang sih doaku? Apa kurang rutin sih sembahyangku?

Silvi: (Menghela Napas Panjang. Mencoba Lebih Sabar) Percaya, percaya. Aku tahu sendiri bagaimana rajinnya kamu berdoa dan sembahyang di depan tuhan. Tapi, bukan hanya itu Patria. Disamping berdoa, sembahyang, pasrah kepada tuhan, sebelumnya kita juga harus berusaha.

Pada Data (05) terdapat tuturan tersebut mengandung maksim kesim-patisan karena antara Patria dan Silvi adalah bersahabat. Silvi menyam-paikan rasa simpati kepada Patria atas kerja keras selama menghadapi Ujian Nasional. Kesimpatisan yang diberikan Silvi tersebut diikuti dengan nasihat agar Patria selalu sabar dalam menghadapi cobaan yang sudah diberikan oleh Tuhan tentang hasil Ujian Na-sional tidak lulus.

\section{Relevansi Kumpulan Naskah Drama Geng Toilet sebagai Bahan Ajar Teks Drama di Sekolah Menengah Atas}

Relevansi kumpulan naskah drama Geng Toilet karya Sosiawan Leak sebagai materi ajar pembelajaran teks drama kelas XI dan XII SMA yaitu (1) terdapat struktur kebahasaan pada dialog kumpulan naskah drama tergolong mudah dipahami karena menggunakan bahasa sehari-hari; (2) berdasarkan data hasil analisis kuri-kulum, teks drama menjadi bagian dari kompetensi dasar siswa kelas XI dan XII SMA yang harus dicapai dalam kompetensi dasar siswa kelas XI dan XII SMA dalam kurikulum 2013 (revisi/terbaru) sehingga kumpulan naskah drama Geng Toilet berisi nas-kah ringan dan berdurasi pendek yang cocok sebagai bahan ajar teks drama di kelas; (3) mengacu pada struktur pe-nulisan dan pemilihan tema dalam kumpulan naskah drama Geng Toilet menggunakan urutan sesuai dengan emosi pembaca dan mengambil cerita dari pengalaman dan kehidupan di sekitar masyarakat sehingga kumpulan naskah drama tergolong menarik dan tidak mudah membosankan, (4) mengacu pada data hasill wawancara dari 
informan mengenai tindak tutur dan prinsip kesantunan berbahasa dan rele-vansi terhadap kumpulan naskah drama Geng Toilet karya Sosiawan Leak sebagai bahan ajar pembelajaran teks drama, dapat membuktikan bahwa naskah drama tersebut dapat digu-nakan sebagai alternatif pembelajaran sastra, khususnya pembelajaran teks drama siswa kelas XI dan XII SMA.

\section{SIMPULAN}

Berdasarkan hasil analisis data dan pembahasan yang telah diuraikan pada pembahasan diatas dapat disim-pulkan bahwa Tindak tutur yang ditemukan dalam dialog kumpulan naskah drama Geng Toilet berdasarkan tindakan yang berkaitan dengan ujaran adalah tindak tutur lokusi, ilokusi, dan perlokusi. Adapun berdasarkan tindakan yang berkaitan dengan strukturnya adalah

\section{REFERENSI}

Asmaniah, Z. (2015). Naskah Drama Rajapati Karangan Ahmad Bakri (Kajian Struktural dan Pragmalinguistik). Jurnal Lokabasa, (6), 219-226. Diperoleh pada Selasa 28 Februari 2018, pukul 9:55:19 WIB, dari

http://id.portalgaruda.org/index.php?re $\mathrm{f}=$ browse \&mood=viewarticle\&article $=448811$

Endrasmoro, C. (2015). Unsur Pembangun Kumpulan Naskah Drama Geng Toilet Karya Sosiawan Leak. Skripsi Tidak Dipublikasikan. Universitas Negeri Semarang, Semarang.

Kirana, C., Suwandi, S., dan Anindyarini, A. (2015). Penerapan Metode Pemodelan untuk Meningkatkan Motivasi Belajar dan Keterampilan Menulis Naskah Drama Siswa Kelas XI IPA 3 SMA Negeri Kebakkramat. Jurnal Penelitian Bahasa, Sastra Indonesia, dan tindak tutur langsung dan tindak tutur tidak langsung.

Selanjutnya, prinsip kesan-tunan ditemukan dalam dialog kum-pulan naskah drama Geng Toilet adalah maksim kecocokan atau per-mufakatan, maksim kemurahan atau kedermawanan, maksim penerimaan atau pujian atau penghargaan, maksim kerendahan hati atau kesederhanaan, dan maksim kesimpatisan.

Berdasarkan analisis data dari informan pembelajaran sastra di kelas XI dan XII SMA terkait dengan pem-belajaran teks drama yang terdapat dalam Kompetensi Dasar pada Kuri-kulum 2013/revisi, maka dapat disim-pulkan bahwa kumpulan naskah drama Geng Toilet dapat digunakan sebagai alternatif pembelajaran sastra, khu-susnya pembelajaran teks drama siswa kelas XI dan XII SMA.

Pengajarannya, (3), 1-15. Diperoleh pada Senin 12 Februari 2018, pukul 2:42:20 WIB, dari http://jurnal.fkip.uns.ac.id/index.php/b hs_indonesia/article/view/7799

Narbuko, C. dan Achmadi, A. (2016). Metodologi Penelitian. Jakarta: PT Bumi Aksara.

Rahmawati, R. (2014). Analisis Kesantuan Berbahasa di Lingkungan Terminal Sekitar Wilayah Bojonegoro dengan Prinsip Kesantunan Leech. Jurnal Edu Kata, (1), 149-158. Diperoleh pada Minggu 14 Januari 2018, pukul 2:42:23 WIB, dari http://journal.unisda.ac.id/index.php/E DU-KATA/article/view/56

Rohmadi, M. (2004). Pragmatik Teori dan Analisis. Yogyakarta: Lingkar Media. Sugijono. (2016). Memahami Penelitian Kualitatif. Bandung: Alfabeta. 
Sulistyo, E.T. (2013). Pragmatik Suatu Kajian Awal. Surakarta. Sebelas Maret University Press.

Sumarlam, dkk. (2017). Pemahaman dan Kajian Pragmatik. Solo: Bukukatta.

Waluyo, H.J. (2003). Drama Teori dan Pengajarannya. Yogyakarta: Hanindita Graha Widia. (2006). Drama Naskah, Pementasan dan Pengajarannya. Surakarta: UNS Press.

Widyahening, E.T., dkk. (2012). Kajian Drama Teori dan Implementasi. Surakarta: Cakrawala Media.

Wijana D.P. dan Rohmadi, M. (2011). Analisis Wacana Pragmatik Kajian Teori dan Analisis. Surakarta: Yuma Pustaka.

Yule, G. (2006). Pragmatik. Yogyakarta: Pustaka Pelajar. 